\title{
Um ensaio sobre mortes violentas e incidências criminais no Brasil: uma análise
}

\section{descritiva do panorama nacional}

\author{
An essay on violent deaths and criminal incidences in Brazil: a descriptive analysis of the national
}

panorama

Un ensayo sobre muertes violentas e incidencias delictivas en Brasil: un análisis descriptivo del panorama nacional

Recebido: 13/01/2022 | Revisado: 21/01/2022 | Aceito: 21/01/2022 | Publicado: 23/01/2022

Leonardo de Andrade Carneiro ORCID: https://orcid.org/0000-0003-2388-7516 Universidade Federal do Tocantins, Brasil E-mail:leodpalmas@hotmail.com

\begin{abstract}
Resumo
Este trabalhou tem como escopo apresentar o panorama dos agentes privados de liberdade (APL) e as vítimas de mortes violentas no Brasil, evidenciando características sociais e tipos penais. Diversos estudos no Brasil enfatizam que a criminalidade está intrinsecamente relacionada a diversos fatores como o uso de armas de fogo, tráfico de drogas e estrutura urbana precária. Dessa maneira, os procedimentos adotados para atingir os objetivos dessa pesquisa são os descritivos e a abordagem quantitativa. Os dados e informações foram coletados nos relatórios e documentos do Fórum Brasileiro de Segurança Pública, Instituto de Pesquisa Econômica Aplicada/Atlas da Violência (2021), Instituto Brasileiro de Geografia e Estatística, Departamento Penitenciário Nacional e Sistema de Informação do Departamento Penitenciário Nacional. Os achados sugerem que a criminalidade violenta no Brasil possui características e circunstâncias que afetam todas as cidades e vitima diversas pessoas, de crianças a idosos, através de homicídio, latrocínio ou lesão corporal seguida de morte, com o uso de arma de fogo, arma branca ou agressão. Os agentes que cometem os crimes e estão presos são adultos com idade entre 18 e 34 anos, são solteiros, autodeclarados pardos, com baixa escolaridade e as maiores incidências criminais são o tráfico de drogas.
\end{abstract}

Palavras-chave: Criminalidade violenta; Encarceramento; Mortes violentas.

\begin{abstract}
This work aims to present the panorama of agents deprived of liberty (APL) and victims of violent deaths in Brazil, highlighting social characteristics and criminal types. Several studies in Brazil emphasize that crime is intrinsically related to several factors such as the use of firearms, drug trafficking and precarious urban structure. Thus, the procedures adopted to achieve the objectives of this research are descriptive and quantitative approach. Data and information were collected in the reports and documents of the Brazilian Public Security Forum, Institute of Applied Economic Research/Atlas da Violence (2021), Brazilian Institute of Geography and Statistics, National Penitentiary Department and National Penitentiary Department Information System. The findings suggest that violent crime in Brazil has characteristics and circumstances that affect all cities and victimizes several people, from children to the elderly, through homicide, robbery or bodily injury followed by death, with the use of firearms, white weapons. or aggression. The agents who commit the crimes and are in prison are adults between the ages of 18 and 34, single, self-declared brown, with low education and the highest criminal incidences are drug trafficking.
\end{abstract}

Keywords: Violent crime; Incarceration; Violent deaths.

\section{Resumen}

Este trabajo tiene como objetivo presentar el panorama de los agentes privados de libertad (APL) y víctimas de muertes violentas en Brasil, destacando características sociales y tipos delictivos. Varios estudios en Brasil enfatizan que el crimen está intrínsecamente relacionado con varios factores como el uso de armas de fuego, el tráfico de drogas y la estructura urbana precaria. Así, los procedimientos adoptados para lograr los objetivos de esta investigación son de enfoque descriptivo y cuantitativo. Los datos y la información fueron recopilados en los informes y documentos del Foro Brasileño de Seguridad Pública, Instituto de Investigación Económica Aplicada/Atlas da Violencia (2021), Instituto Brasileño de Geografía y Estadística, Departamento Penitenciario Nacional y Sistema de Información del Departamento Penitenciario Nacional. Los hallazgos sugieren que el crimen violento en Brasil tiene características y circunstancias que afectan a todas las ciudades y victimiza a varias personas, desde niños hasta ancianos, mediante homicidio, robo o lesiones corporales seguidas de muerte, con uso de armas de fuego, armas blancas o agresión. Los 
agentes que delinquen y se encuentran en prisión son adultos de entre 18 y 34 años, solteros, autodeclarados morenos, con baja escolaridad y la mayor incidencia delictiva es el narcotráfico.

Palabras clave: Crimen violento; Encarcelamiento; Muertes violentas.

\section{Introdução}

A criminalidade violenta no Brasil vem se intensificando desde a década de 70 principalmente nos centros urbanos. Ela é um problema atual e, "além das perdas humanas", produz implicações para o desenvolvimento socioeconômico, aumentando ainda mais as desigualdades sociais da sociedade (Nóbrega Júnior et al., 2009, p. 75). Esse fenômeno atinge homens entre 15 a 29 anos com baixa escolaridade e está associado a diversos fatores. Os principais são o tráfico de drogas, porte e uso de armas de fogo, desigualdade socioeconômica, falta de infraestrutura nas comunidades e ausência de controle social formal e informal (Misse, 2006; Nóbrega Júnior, Zaverucha \& Rocha, 2009; Costa \& Lima, 2018).

A criminalidade violenta atinge todas as sociedades, em especial as da América Latina, que se apresenta como uma região violenta. Segundo Asmann e O'reilly (2020), o ano de 2019 foi marcado pelo aumento sistemático de mortes violentas, com destaque para o homicídio, que reacendeu novas discussões acerca dos problemas ocasionados pela violência. Segundo os pesquisados, esse aumento está relacionado principalmente ao tráfico de drogas e à luta armada entre organizações criminosas.

De acordo com Campos e Santos (2004), as principais práticas criminosas que movimentam o crime no Brasil são o tráfico de drogas, tráfico de armas e assaltos. Nesse sentido, Soares Filho, Merchan-Hamann e Vasconcelos (2020) afirmam que os estados da região Sudeste nos últimos anos diminuíram o número de mortes violentas (MV), contudo os do Norte e Nordeste tiveram um aumento acentuado. Ressalta que homens jovens, com baixa escolaridade e com envolvimento com o tráfico de drogas e álcool são as principais vítimas. A maior parte das MV ocorreram "por armas de fogo, em vias públicas de áreas mais pobres de grandes cidades brasileiras, principalmente em estados da região Nordeste” (Soares Filho et al., 2020, p. 3098).

A região Norte destaca-se como um território com diversidade de situações relacionadas à criminalidade violenta como o "narcotráfico, desmatamento, grilagem de terras, garimpos ilegais", tráfico de drogas e pistolagem etc. (De Lima, Bueno \& Alcadipani, 2021, p. 26). Essas ações afetam a coesão social e modificam as estruturas sociais.

Em trabalhos publicados recentemente (Carneiro \& Oliveira, 2020) e (Carneiro \& Silva, 2020) evidenciam dados e informações sobre criminalidade violenta e políticas públicas no Brasil. Apresentam um panorama no Brasil, com destaque para a região norte do Brasil, relacionam crimes letais intencionais e suas implicações no desenvolvimento local. Para os autores, o crime e a violência urbana são distúrbios que afetam todo o território brasileiro, em todos os níveis sociais, transformando a maioria dos grandes centros urbanos em palco de guerra.

De forma geral, a criminalidade violenta está associada a questões econômicas. Ela é um "setor econômico" que se utiliza de diversos mecanismos para manter-se ou expandir sua atuação. Para isso, diferentes pessoas morrem ou são presas e há um padrão de escolaridade, cor e outros referenciais semelhantes entre as pessoas que morrem e as que estão encarceradas (Tavares, Catalan, Romano, \& Melo, 2016, p. 929). Nessa perspectiva, um dos principais fatores apontados pelos cientistas sociais para o aumento das mortes violentas é as facções ou organizações criminosas que "surgiram no interior de prisões, fortaleceram-se dentro dessas instituições e acabaram se espraiando para fora" (Sapori, 2019, p. 202). Por isso as prisões são um solo fértil para o recrutamento de novos criminosos para uma carreira de atividades ilegais.

Diante dessas considerações iniciais, esse trabalho tem como escopo apresentar de maneira descritiva o espaço da criminalidade no Brasil e no estado do Tocantins por meio de características sociais e perfis dos agentes privados de liberdade (APL) e vítimas de mortes violentas. 


\section{Procedimentos Metodológicos}

Este trabalho apresenta as principais características e perfis das vítimas de mortes violentas e a conjuntura das pessoas privadas de liberdade no Brasil. O objetivo é verificar se existe relação entre o perfil das vítimas e o dos presos no sistema prisional. Nessa perspectiva, Quivy (1992, p. 31) afirma que "uma investigação é, por definição, algo que se procura". Sendo assim, essa pesquisa busca delinear os padrões, tipos e indicadores criminais no Brasil e no Estado do Tocantins. A propositura é apresentar quantitativamente, através de Figuras e tabelas, os tipos penais, raça/cor, nível de escolaridade, idade e outras informações necessárias para a construção do espaço social do criminoso.

Para realizar essa tarefa, foi utilizada a abordagem quantitativa que focaliza "uma quantidade pequena de conceitos". Quanto à classificação, essa é uma pesquisa descritiva, que "têm como objetivo primordial a descrição das características de determinada população" (Gerhardt e Silveira, 2009, p. 34; Gil, 2010, p. 28). Os dados e informações dessa investigação foram coletados nos relatórios e documentos do Fórum Brasileiro de Segurança Pública (FBSP); Instituto de Pesquisa Econômica Aplicada (IPEA)/ Atlas da Violência (2021); Instituto Brasileiro de Geografia e Estatística (IBGE); Departamento Penitenciário Nacional (Depen) e Sistema de Informação do Departamento Penitenciário Nacional (Sisdepen), que é a plataforma de estatísticas que sintetiza as informações sobre os estabelecimentos penais e a população carcerária. "Essas informações são periodicamente atualizadas pelos gestores das unidades prisionais" (Sisdepen, 2021). Com base nesses dados, foi possível elaborar as tabelas e Figuras que subsidiaram as discussões e apontamentos desta pesquisa.

\section{Resultados e Discussão}

Segundo pesquisa realizada pelo Núcleo de Estudos da Violência da USP (NEV-USP) em parceria com o Monitor da Violência (2021) e Instituto de Pesquisa Econômica Aplicada (IPEA), no Brasil, entre 2019 e 2020, cerca de 91.778 pessoas morreram de forma violenta através de homicídio doloso, latrocínio e lesão corporal seguida de morte. Em 2019, cerca de 47.796 e em 2020, próximo a 43.892. A taxa é de 22,7 e 20,89 por 100 habitantes. Esses números são assustadores, porém menores em comparação aos dos anos anteriores, com destaque para 2016, que teve 62.517 mortes e 2017 com 65.602 mortes violentas, período histórico no Brasil. A taxa média de mortes violentas, em 2020, foi de 20,89 (homicídio doloso, latrocínio e lesão corporal seguida de morte), por grupo de 100 mil habitantes, uma média alta em comparação a outros países da América Latina. Esse fenômeno desperta interesse em compreender quais fatores e práticas podem ter influenciado a redução das mortes violentas.

Mesmo com a diminuição desses eventos, alguns estados possuem taxas acima da média nacional, com destaque para a região Norte e Nordeste. Entre os estados da região Norte, em números absolutos, o Pará apresenta a maior taxa com cerca de 3.485 mortes violentas, o que representa 54\% das mortes. Se a avaliação for por grupo de 100 mil habitantes, os estados com maior índice de mortes em 2019 foram Amapá (49,1), Pará (40,5), Acre (36,2), Roraima (35), Amazonas (27,7), Rondônia $(25,9)$ e Tocantins $(24,2)$, todos com taxas acima da média nacional. No Nordeste, os estados de Sergipe $(42,1)$, Rio Grande do Norte $(40,7)$, Bahia $(39,2)$ e Alagoas $(34,2)$ são os destaques.

Já em relação ao perfil de encarceramento no Brasil, ele é formado por pessoas entre 18 e 45 anos, a maioria não possui filhos, são autodeclaradas pardas e possuem o ensino fundamental incompleto.

\subsection{Pessoas privadas de liberdade no Brasil}

Nas últimas duas décadas, o número de pessoas privadas de liberdade teve um aumento de 224,5\%. Percebe-se que as ações no combate à criminalidade, por meio da dissuasão, não estão surtindo os efeitos necessários, ocasionado um aumento assustador do número de pessoas presas. Nesse contexto, a Figura 1 demonstra a evolução do encarceramento no Brasil. 
Figura 1. Evolução do Encarceramento no Brasil, 2000 - 2020.

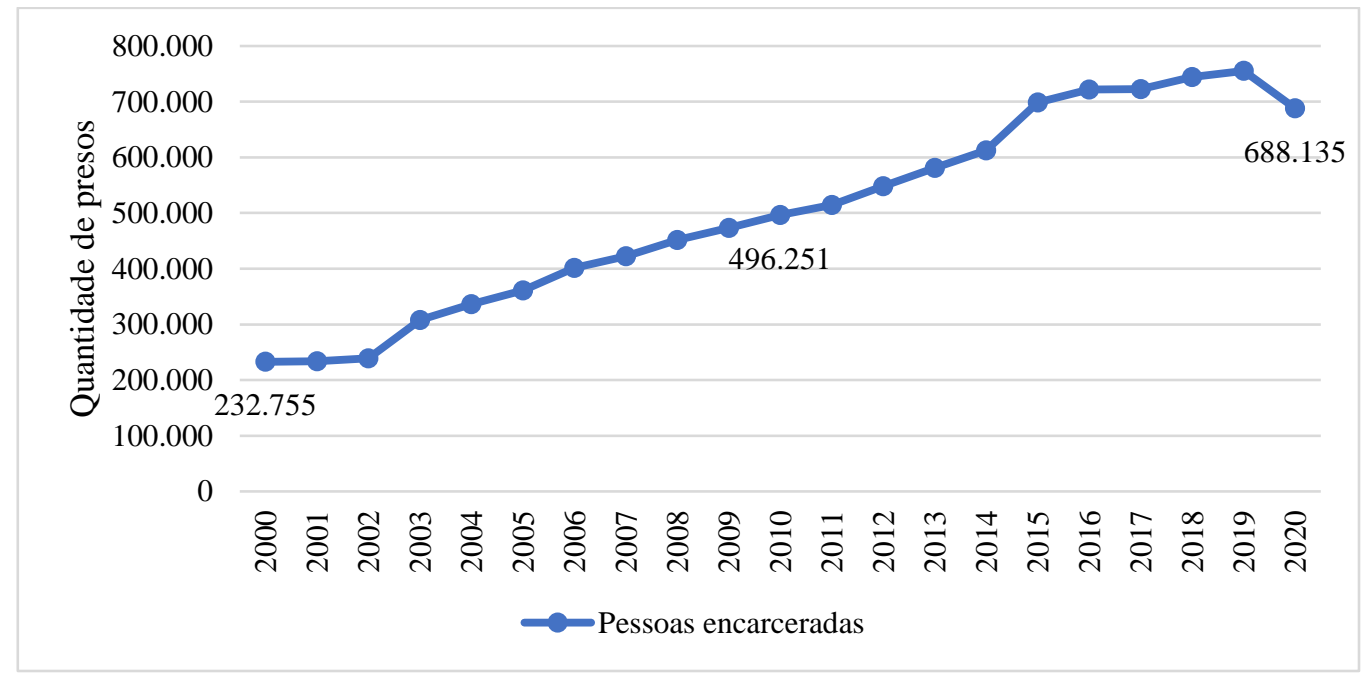

Fonte: Elaborada pelo autor com base em informações do Depen (2020).

Segundo Ribeiro, Martino e Duarte, (2021), a maior causa das prisões no Brasil está relacionada ao tráfico de drogas. Entre os privados de liberdade por esse motivo, 28,84\% são homens e 56,16\% são mulheres. O tráfico de drogas representa um dos grandes problemas a serem resolvidos pelas instituições públicas e sociedade civil. Segundo informações do Depen (2021) ${ }^{1}$, as principais razões de encarceramento no Brasil são:

- $\quad$ crimes cometidos por mulheres, número absoluto e porcentagem: tráfico de drogas: 15.205 (56,16\%); contra o patrimônio: $6.781(25,05 \%)$ e contra pessoa $3.008(11,11 \%)$;

- $\quad$ crimes cometidos por homens: tráfico de drogas: 193.325 (28,84\%); contra o patrimônio: 278.568 (41,55\%) representado por um conjunto de crimes como roubo, furto, estelionato e outros; e contra pessoa 102.551 (15,3\%).

A Figura 2 ilustra o cenário nacional sobre os dados dos principais tipos de crimes que ocorrem no Brasil.

Figura 2. Percentual de incidência por crime em 2020.

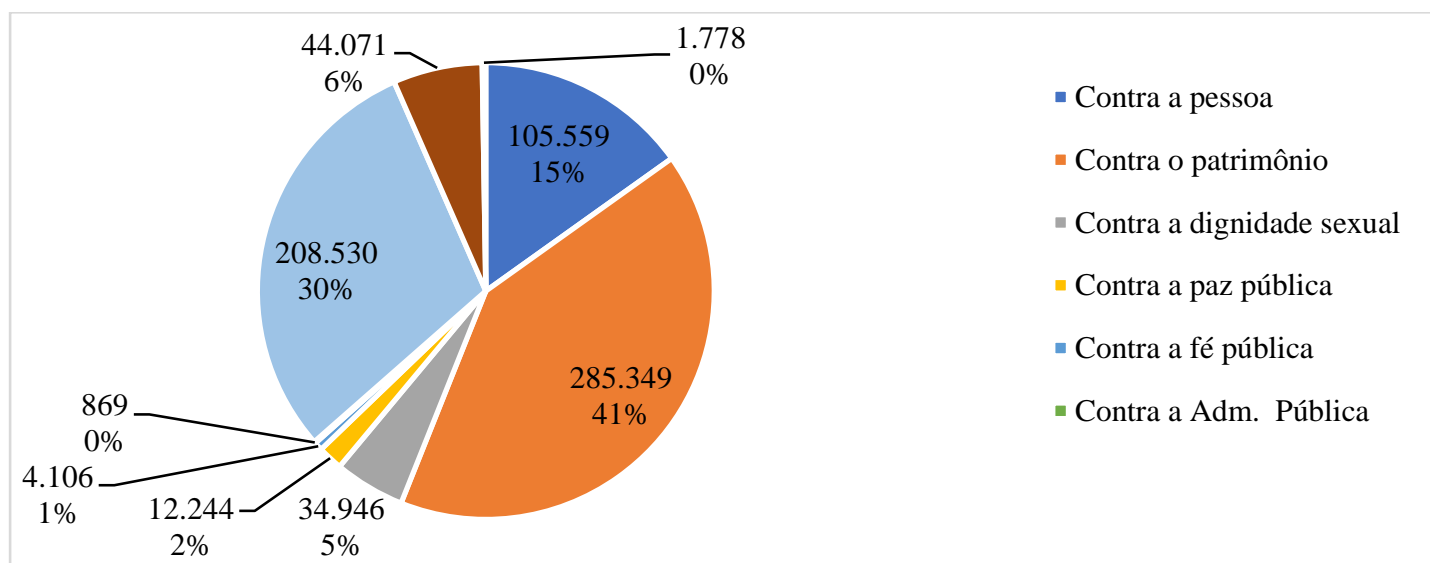

Fonte: Elaborada pelo autor com base em informações do Depen (2020). Dados disponíveis em: https://www.gov.br/depen/pt-br/sisdepen.

\footnotetext{
${ }^{1}$ Contra o patrimônio: furto, roubo, latrocínio, extorsão, extorsão mediante sequestro, apropriação indébita, apropriação indébita previdenciária, estelionato, receptação, outros - não listados acima entre os artigos 156 e 179. Contra pessoa: homicídio, aborto, lesão corporal, violência doméstica, sequestro e cárcere privado, não listados acima entre os artigos 122 e 154-A.
} 
Os crimes de menor potencial ofensivo (contra a paz pública, fé pública e administração pública) são os com menos prisões, contudo isso não configura que esses delitos não ocorram. Outros crimes que representam um grande problema para a sociedade brasileira estão relacionados à dignidade sexual, que envolve o crime de estupro, atentado violento ao pudor, estupro de vulnerável, corrupção de menores, tráfico internacional de pessoa para fim de exploração sexual, tráfico interno de pessoa para fim de exploração sexual e crimes que estão relacionados nos Artigos 215, 216-A, 218-A, 218-B, 227, 228, 229, 230, todos do Código Penal Brasileiro (CP).

Nessa perspectiva, no ano de 2020, segundo o Depen (2021), cerca de 335.773 (50,26\%) pessoas privadas de liberdade estavam condenadas e 215.317 (32,23\%) estavam presas provisoriamente. No regime semiaberto eram 106.826 (15,99\%) e no aberto $7.539(1,13 \%)$, totalizando 688.135 mil presos. Desse total, 639.477 (95,71\%) são do sexo masculino e $28.688(4,29 \%)$ do sexo feminino. Em relação à faixa etária, constata-se que a maioria é jovem adulta e 284.819 está na idade entre 18 a 29 anos, ou seja, $41,4 \%$ de presos (Figura 3 ).

Figura 3. População prisional por faixa etária no Brasil em 2020.

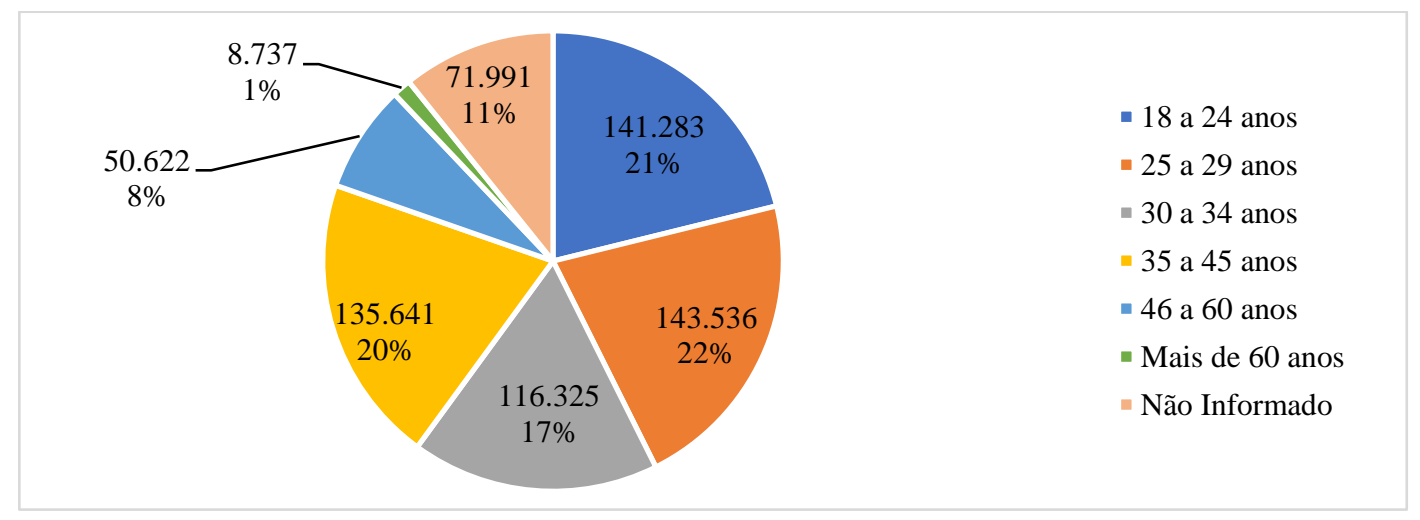

Fonte: Elaborada pelo autor com base em informações do Depen (2020).

Percebe-se que a idade da população de presos é entre 18 a 45 anos e que $21 \%$ estão na faixa etária entre 18 a 24 anos e $42 \%$ estão com idade entre 30 a 45 . Essas pessoas poderiam estar contribuindo para o desenvolvimento da sociedade exercendo papéis sem pertencerem ao campo da criminalidade (Figura 3). Nesse contexto, que fatores podem favorecer que essas pessoas entrem e permaneçam nesse campo?

Em relação à composição familiar, quase a maioria não possui filhos (Figura 4). O Depen (2021) apresenta um relatório com os percentuais, que são os seguintes: sem filhos: 84.574 presos (48\%); um filho: 42.222 (24\%); dois filhos: 24.934; três filhos: 13.106; quatro filhos: 7.057; acima de cinco filhos: 5.572 .

Figura 4. Número de filhos das pessoas privadas de liberdades no Brasil em 2020.

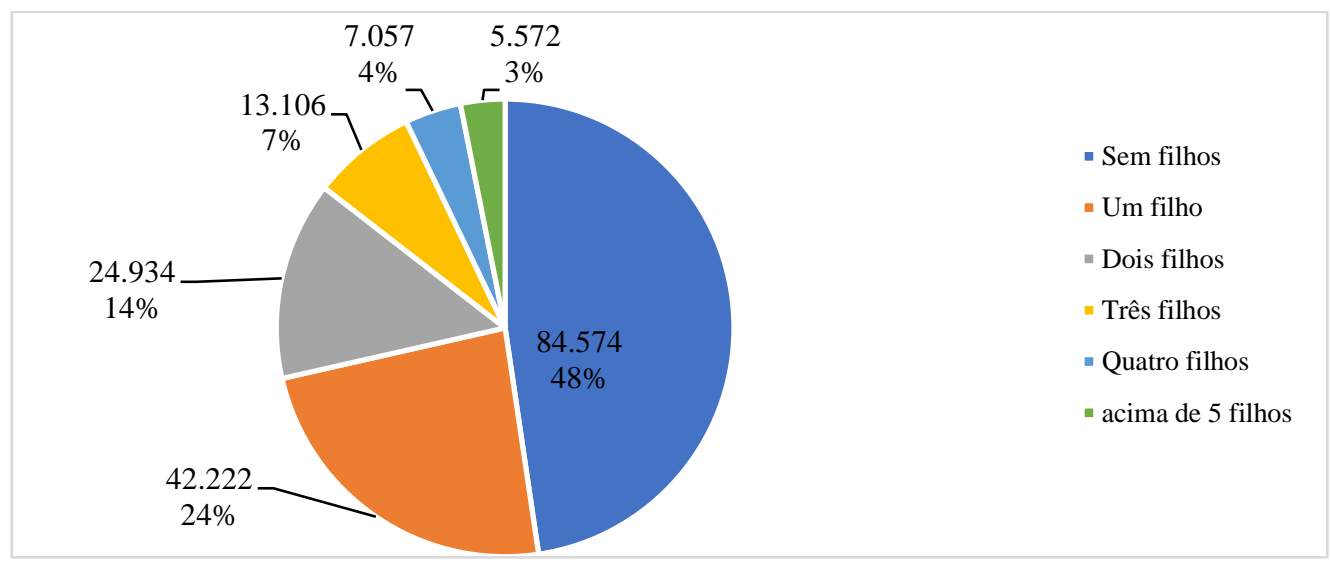

Fonte: Elaborada pelo autor com base em informações do Depen (2020). 
Quanto à cor da pele, o Depen tem informações de apenas 177.465 presos. Por isso, não é possível apresentar dados precisos desse perfil da população carcerária (Figura 5). Em relação à cor/raça, a maioria se autodeclara parda (44\%) e branca $28 \%$, conforme pode ser observado na Figura 5.

Figura 5. Dados da população prisional em relação à cor e raça no Brasil em 2019.

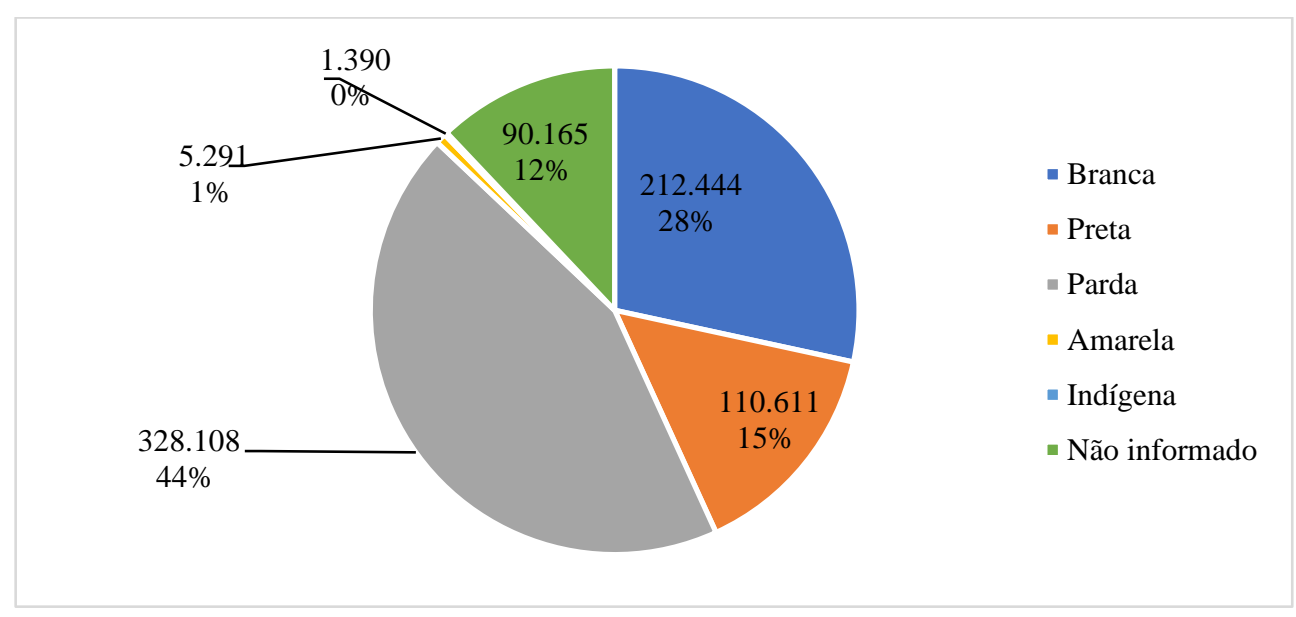

Fonte: Elaborada pelo autor com base em informações do Depen (2019).

Em relação aos níveis de escolaridade dos APL no Brasil, 60\% possuem o ensino fundamental completo ou incompleto. Já os presos com ensino médio completo representam 9\% e incompleto 14\%, perfazendo um total de $23 \%$. Em relação aos presos com escolaridade de nível superior completo e incompleto, o quantitativo é bem menor, representando $2 \%$ da população carcerária. Podemos afirmar que as pessoas privadas de liberdade possuem baixa escolaridade (Figura 6).

Figura 6. Nível de escolaridade das pessoas privadas de liberdade do Brasil em 2019.

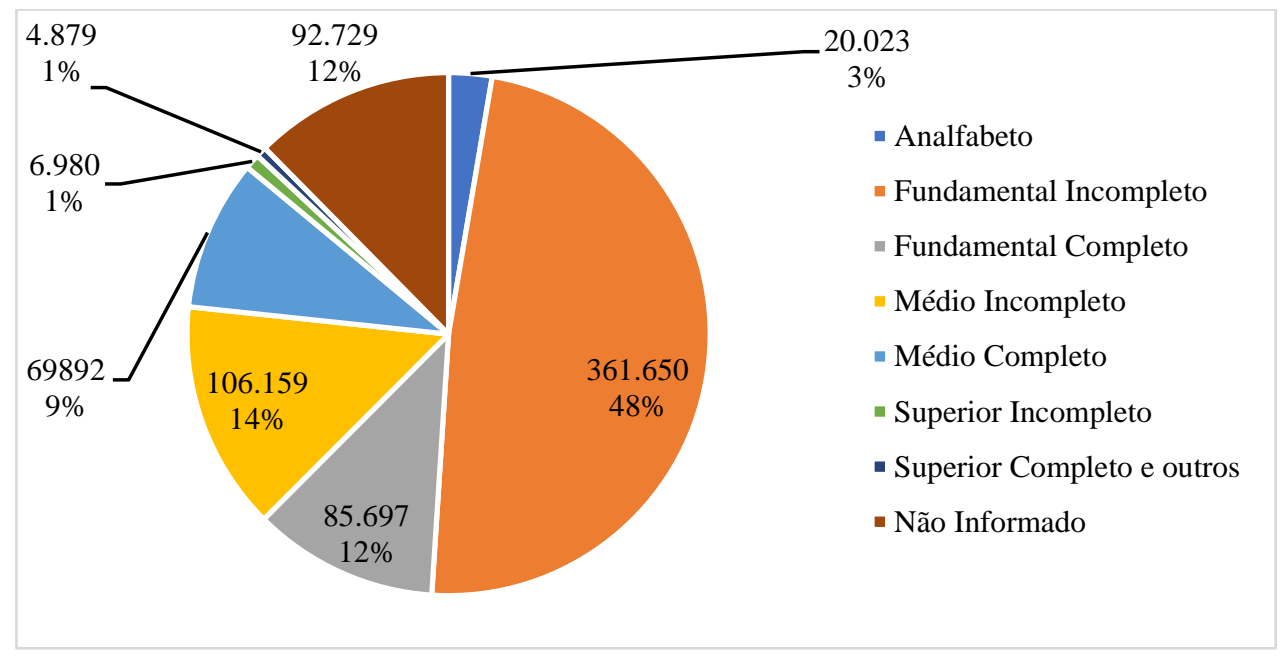

Fonte: Elaborada pelo autor com base em informações do Depen (2019).

Os dados demonstram que a maioria dos APL são adultos com idade entre 18 e 45 anos, foram presos por crimes relacionados ao tráfico de drogas e contra pessoa e patrimônio, não possuem filhos e possuem baixa escolaridade.

\subsection{Análise dos presos no Estado do Tocantins e Palmas/Tocantins}

O espaço da criminalidade, de certo modo, apresenta certas características, e esta subseção descreve o perfil, qualidade distintiva e os principais tipos penais dos presos do Estado do Tocantins. Em 2020, o Tocantins tinha o quantitativo de 4.118 
pessoas privadas de liberdade. Sendo que deste total, 3.888 (94\%) do sexo masculino e 230 (6\%) feminino. Presos sem condenação representavam 39\% e com condenação 48\%. Ou seja, 1.590 (39\%) estavam presos provisoriamente, e 1.994 (48\%) eram condenados. Conforme a Secretaria de Cidadania e Justiça do Estado do Tocantins, 524 (13\%) eram presos em regime semiaberto (Figura 7 e Tabela 1) (Tocantins, 2021)

Figura 7. Quantidade de presos no Tocantins em 2020.

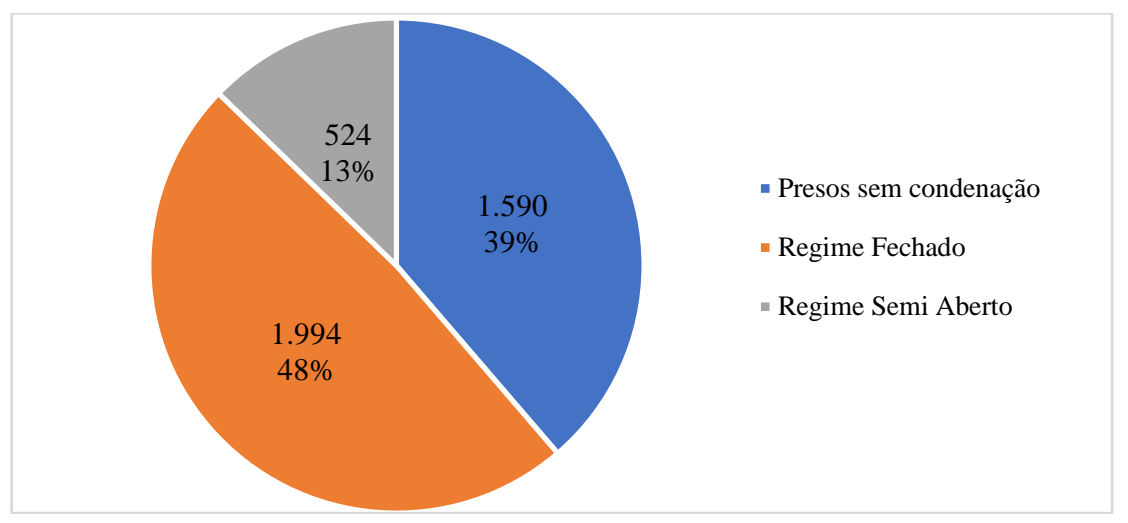

Fonte: Elaborada pelo autor com base em informações da Secretaria de Cidadania e Justiça do Estado do Tocantins.

Conforme observado, os presos em geral são condenados em regime fechado (Tabela 1), tanto homens, quanto mulheres. Dessa maneira, o perfil carcerário é composto por características e semelhanças homogêneas.

Tabela 1. Presos encarcerados no Estado do Tocantins em 2020.

\begin{tabular}{llllllll}
\hline Presos & Homens & Freq. Rel. $*$ & Freq. Ac. & Mulheres & Freq. Rel. & Freq. Ac. & Total \\
\hline Sem condenação & 1.463 & $38 \%$ & $38 \%$ & 127 & $55 \%$ & $55 \%$ & 1.590 \\
Regime Fechado & 1.936 & $49,74 \%$ & $87,74 \%$ & 58 & $25 \%$ & $80 \%$ & 1.994 \\
Semiaberto & 479 & $12 \%$ & $99,74 \%$ & 45 & $20 \%$ & $100 \%$ & 524 \\
Internação & 10 & $0,26 \%$ & $100 \%$ & 0 & 0 & $100 \%$ & 10 \\
\hline Total & $\mathbf{3 . 8 8 8}$ & $\mathbf{1 0 0 \%}$ & & $\mathbf{2 3 0}$ & $\mathbf{1 0 0 \%}$ & & $\mathbf{4 . 1 1 8}$ \\
\hline
\end{tabular}

(* Frequência relativa: Freq. Rel.)

Fonte: Elaborada pelo autor com base em informações da Secretaria de Cidadania de Justiça do Estado do Tocantins.

Os dados mostram que a maior parte dos APL do Estado do Tocantins é constituída de pessoas condenadas. Os homens representam 49,74\% e as mulheres $25 \%$. De acordo com a tabela 2, pode-se afirmar que a faixa etária dos presos no Tocantins é constituída de pessoas jovens, seguindo as mesmas característica e perfis dos APL do sistema nacional.

Tabela 2. Pessoas privadas de liberdade por faixa etária e sexo em Tocantins em 2020.

\begin{tabular}{lccccc}
\hline Faixa etária & Homens & Freq. Rel. & Mulheres & Freq. Rel. & Total \\
\hline 18 a 24 anos & 955 & $25 \%$ & 47 & $21 \%$ & 1002 \\
25 a 29 anos & 1024 & $26 \%$ & 70 & $30 \%$ & 1094 \\
30 a 34 anos & 624 & $16 \%$ & 52 & $23 \%$ & 676 \\
35 a 45 anos & 774 & $20 \%$ & 35 & $15 \%$ & 809 \\
46 a 60 anos & 276 & $7 \%$ & 7 & $3 \%$ & 283 \\
61 a 70 anos & 57 & $2 \%$ & 3 & $1 \%$ & 60 \\
Mais de 70 anos & 12 & $0,31 \%$ & 0 & $0 \%$ & 12 \\
Não Informado & 166 & $3,69 \%$ & 16 & $7 \%$ & 182 \\
\hline Total & $\mathbf{3 8 8 8}$ & $\mathbf{1 0 0} \%$ & $\mathbf{2 3 0}$ & $\mathbf{1 0 0} \%$ & $\mathbf{4 1 1 8}$ \\
\hline
\end{tabular}

Fonte: Elaborada pelo autor com base em informações da Secretaria de Cidadania e Justiça do Estado do Tocantins (2021). 
Observa-se que existe um predomínio de indivíduos com idade entre 18 a 29 anos, tanto masculino e feminino no campo da criminalidade. Em relação à cor e raça, ressalta-se as declaradas pardas (54,4\%) (tabela 1). Percebe-se uma simetria com os dados nacionais, que apontam a superioridade do quantitativo dos presos no Brasil que se autodeclararam pardos.

Tabela 3. Pessoas privadas de liberdade por cor de pele/ raça/ etnia no Tocantins em 2020.

\begin{tabular}{lccccc}
\hline \multicolumn{1}{c}{ Presos } & Homens & Freq. Rel. & Mulheres & Freq. Rel. & Total \\
\hline Branca & 543 & $13,9 \%$ & 34 & $0,9 \%$ & 577 \\
Preta & 958 & $23,3 \%$ & 39 & $0,1 \%$ & 997 \\
Parda & 2239 & $54,4 \%$ & 155 & $3,8 \%$ & 2394 \\
Amarela & 51 & $1,23 \%$ & 2 & $0,08 \%$ & 53 \\
Indígena & 5 & $0,05 \%$ & 0 & 0 & 5 \\
Não informado & 92 & $2,24 \%$ & 0 & 0 & 92 \\
\hline \multicolumn{1}{c}{ Total } & $\mathbf{3 8 8 8}$ & & $\mathbf{2 3 0}$ & & $\mathbf{4 1 1 8}$ \\
\hline \multicolumn{1}{c}{} & $\mathbf{9 5 , 1 2 \%}$ & & $\mathbf{4 , 8 8 \%}$ & $\mathbf{1 0 0 \%}$
\end{tabular}

Fonte: Elaborada pelo autor com base em informações da Secretaria de Cidadania e Justiça do Estado do Tocantins (2021).

Assim sendo, que fatores podem estar contribuindo para a participação e permanência de agentes no espaço social da criminalidade? É oportuno frisar que além de adultos entre 18 a 29 anos, os agentes em sua maior parte são solteiros (tabela 4), com baixa escolaridade e sem filhos. Esse perfil é mais propenso a aprender e desenvolver o comportamento criminoso.

Tabela 4. Estado civil das pessoas privadas de liberdade no Tocantins em 2020.

\begin{tabular}{lccccc}
\hline Estado civil & Homens & Freq. Rel. & Mulheres & Freq. Rel. & Total \\
\hline Solteiro & 1908 & $48,66 \%$ & 125 & $54 \%$ & 2033 \\
União estável & 1138 & $29 \%$ & 77 & $34 \%$ & 1215 \\
Casado & 492 & $13 \%$ & 16 & $7 \%$ & 508 \\
Separado & 41 & $1 \%$ & 3 & $1 \%$ & 44 \\
Divorciado & 57 & $2 \%$ & 7 & $3 \%$ & 64 \\
Viúvo & 13 & $0,34 \%$ & 2 & $1 \%$ & 15 \\
Não informado & 239 & $6 \%$ & 0 & 0 & 239 \\
\hline Total & $\mathbf{3 8 8 8}$ & $\mathbf{1 0 0} \%$ & $\mathbf{2 3 0}$ & $\mathbf{1 0 0} \%$ & $\mathbf{4 1 1 8}$ \\
\hline
\end{tabular}

Fonte: Elaborada pelo autor com base em informações da Secretaria de Cidadania e Justiça do Estado do Tocantins (2021).

Em relação à escolaridade, o analfabetismo representa 6\% e fundamental completo ou incompleto, 47\%. Dessa maneira, há paridade nos aspectos educacionais dos criminosos do Tocantins aos do Brasil (Figura 8).

Figura 8. Escolaridade dos presos do estado do Tocantins em 2020.

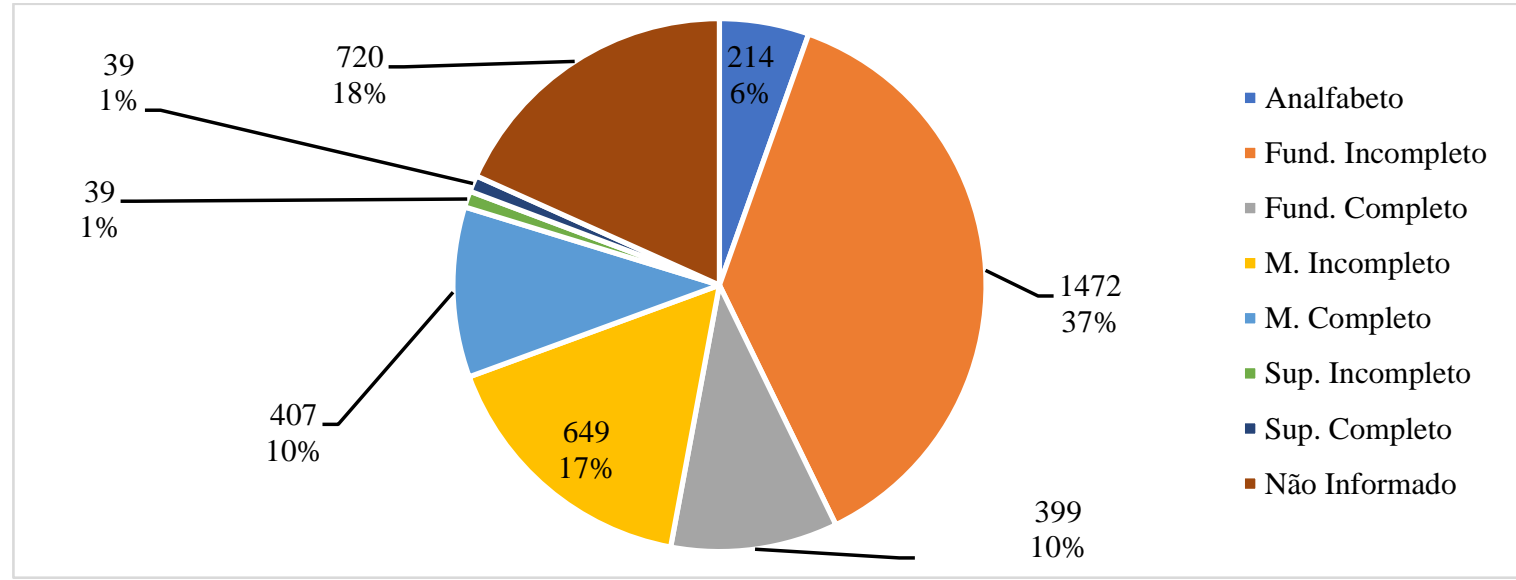

Fonte: Elaborada pelo autor com base em informações da Secretaria de Cidadania e Justiça do Estado do Tocantins (2021). 
Segundo Edelstein (2016), a criminalidade e os criminosos aterrorizam as sociedades como um todo, e o medo do crime danifica as estruturas sociais, provocando mudanças no estilo de vida. Segundo o autor, crimes que ocorrem no dia a dia nas sociedades acontecem principalmente na rua, estacionamentos, escolas, residências e no trabalho. Para Edelstein, esses crimes são praticados por criminosos habituais que cometem a maior parte dos atos delituosos, ou seja, homicídio, roubo, furto, extorsão, latrocínio, lesão corporal etc.

Destaca-se que os criminosos privados de liberdade no Brasil e Tocantins (Figuras 2 e 9) possuem características e aspectos de criminosos habituais, ou seja, as incidências criminais estão principalmente relacionadas ao tráfico de drogas, roubo, homicídios e furto. As informações analisadas e destacadas neste texto demonstram características e observações importantes, sobre o espaço social da criminalidade no Brasil e no Estado do Tocantins. As principais variáveis percebidas nesta investigação evidenciam que os APL são pessoas com idade entre 18 a 45 anos e que as incidências criminais estão relacionadas ao tráfico de drogas, roubo, homicídios e furto. Em relação a indicadores familiares, a maior parte é solteira, não possui filhos e possui baixa escolaridade.

Figura 9. Incidências criminais no Estado do Tocantins em 2019.

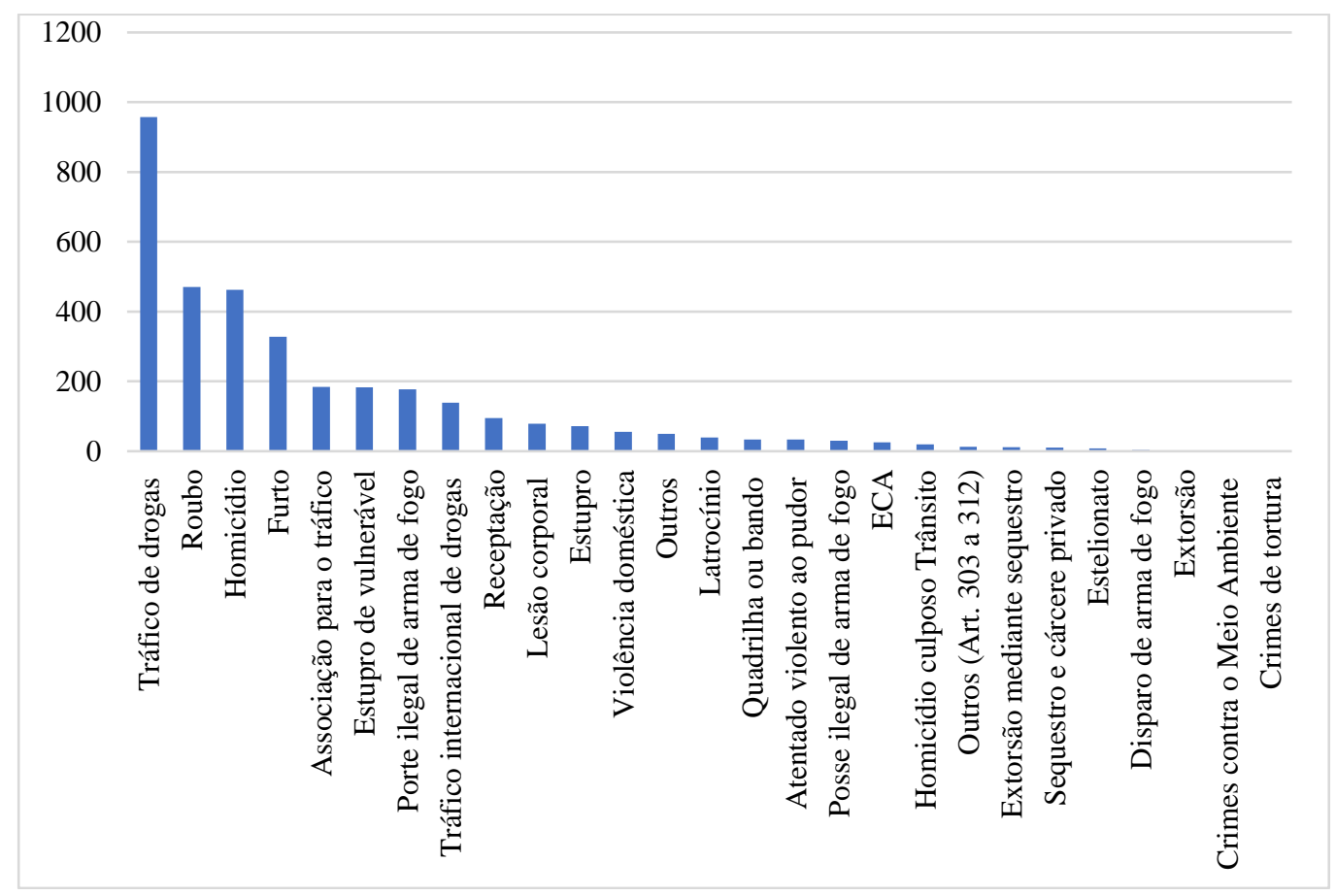

Fonte: Elaborada pelo autor com base em informações da Secretaria de Cidadania e Justiça do Estado do Tocantins (2021).

Portanto as evidências destacadas possibilitam formular um questionamento: se os presos que estão em regime fechado em Palmas, Tocantins, possuem as mesmas características dos do Brasil, quais são os indicadores socioeconômicos correlacionados às incidências criminais?

\subsection{Dados criminais no Brasil}

\subsubsection{Um panorama Nacional}

As Figuras e tabelas abaixo apresentam o cenário da criminalidade nas regiões brasileiras. Os dados e informações foram coletados na base de dados do Instituto de Pesquisa Econômica Aplicada (Ipea), Fórum Brasileiro de Segurança Pública (FBSP), Instituto Brasileiro de Geografia e Estatística (IBGE) e Anuário Brasileiro de Segurança Pública. As Figuras 10 e 11 revelam as séries históricas das mortes violentas que ocorreram no Brasil de 1989 a 2019. Segundo dados do Ipea e FBSP, da população brasileira em geral, os jovens adultos entre 15 a 29 anos são o público que mais morre. Pode-se afirmar que o ápice 
da mortandade no país ocorreu no ano de 2017, com cerca de 65.602 mortes, desse total $54.6 \%$ são de pessoas com idade entre 15 a 29 anos.

Figura 10. Série histórica dos homicídios no Brasil de 1989 a 2019.

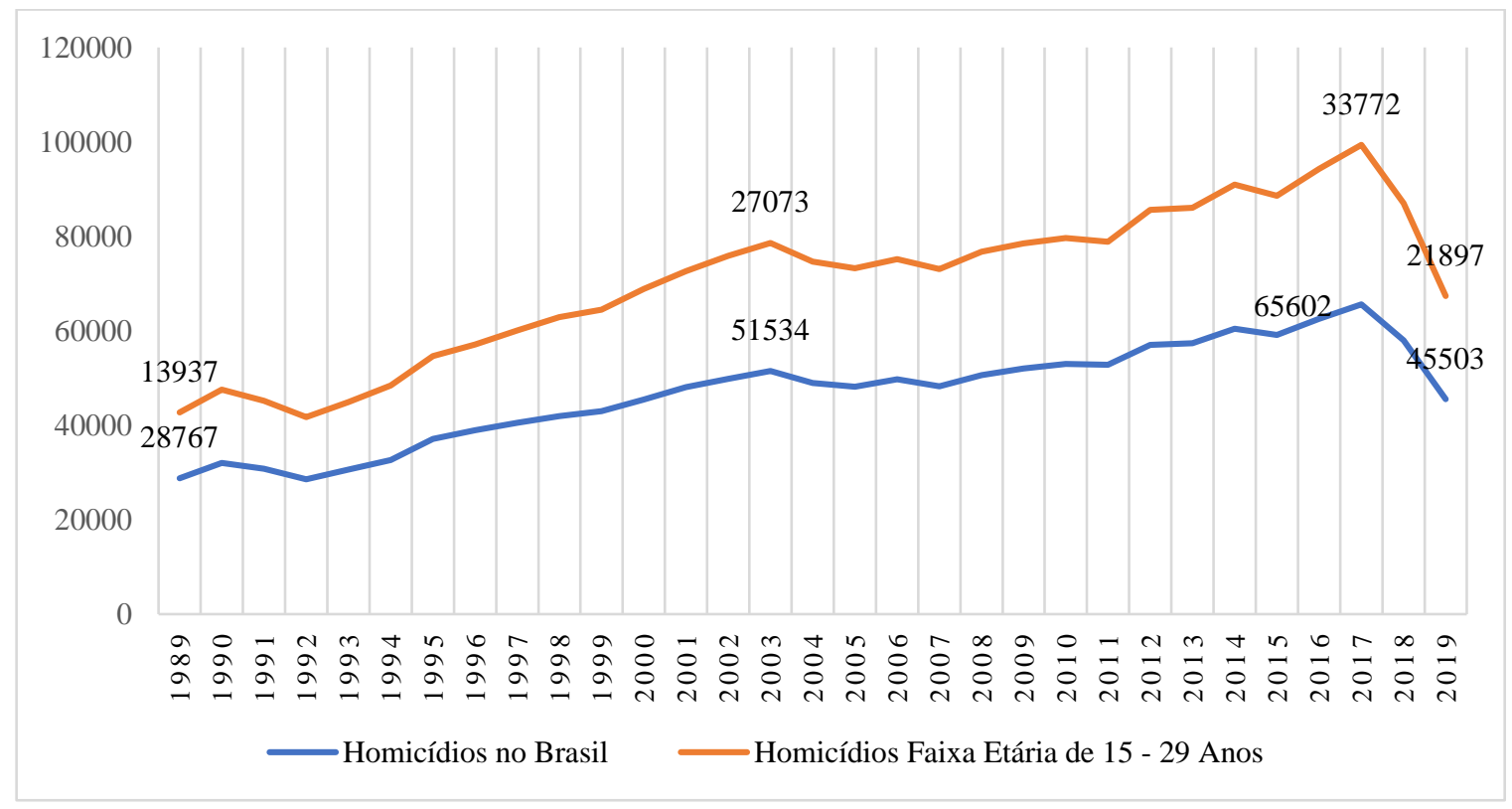

Fonte: Elaborada pelo autor com base em informações Ipea (Adaptado do IPEA, 2020).

Igualmente, entre 2011 e 2019 as mortes violentas intencionais em decorrência de homicídio doloso, latrocínio e lesão corporal seguida de morte tiveram índices alarmantes, conforme observado na Figura 11.

Figura 11. Série histórica de mortes violentas no Brasil entre 2011 e 2019.

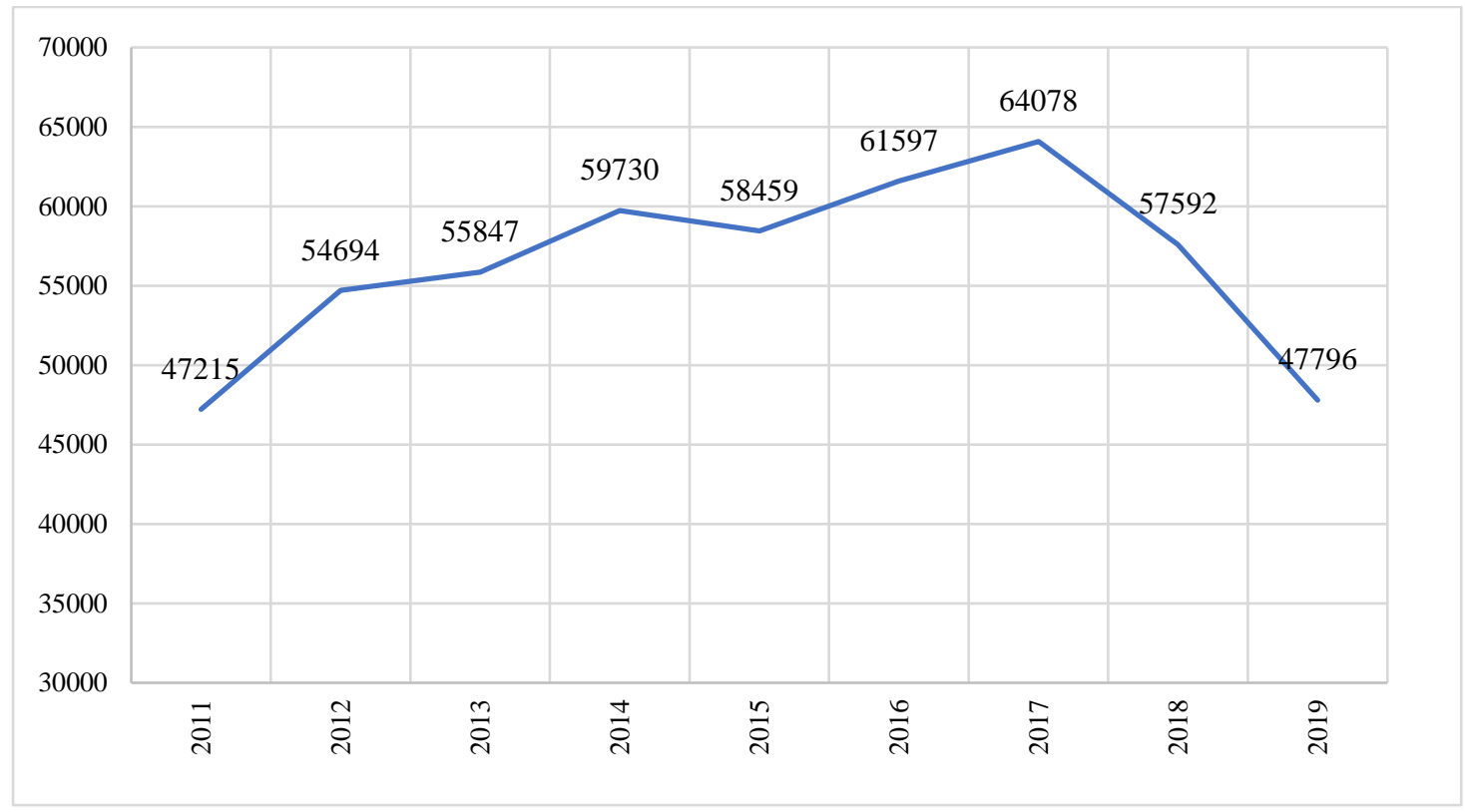

Fonte: Elaborada pelo autor com base em informações Ipea (Adaptado do IPEA, 2020).

Conforme observado, nos últimos cinco anos, as mortes no Brasil diminuíram nas diversas regiões brasileiras. Desse modo, quais fatores e dinâmicas podem ter influenciado a redução da criminalidade? Mesmo com essa diminuição, alguns estados 
possuem taxas de crimes acima da média nacional, que ficou na margem de 22, $7^{2}$ com destaque para a região Norte e Nordeste do Brasil (Figura 15). Em relação ao perfil das vítimas de mortes violentas, aponta-se que as principais assassinadas são as pessoas declaradas pardas e negras (Figura 12), e o principal tipo penal causador das mortes é o homicídio.

Figura 12. Perfil das vítimas por raça/cor e tipo penal no Brasil em 2020.

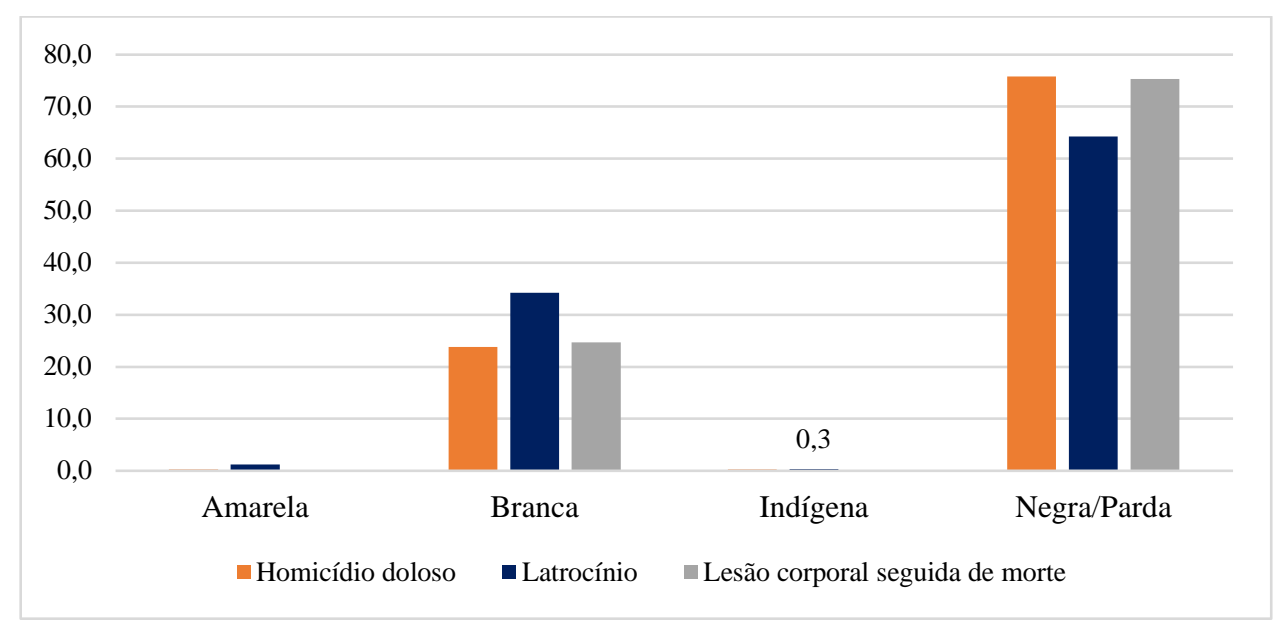

Fonte: Adaptado do $15^{\circ}$ Anuário Brasileiro de Segurança Pública (2021).

Cabe destacar que muitas destas vítimas vivem nos grandes centros urbanos do país, palcos de uma guerra declarada entre facções criminosas e agentes de segurança pública. Conforme vê-se na Figura 13, as principais vítimas de homicídios no Brasil estão na faixa etária entre 18 a 29. Já quando se trata de latrocínios, as pessoas mais idosas são as mais atingidas.

Figura 13. Perfil das vítimas por faixa etária e tipo penal no Brasil em 2020.

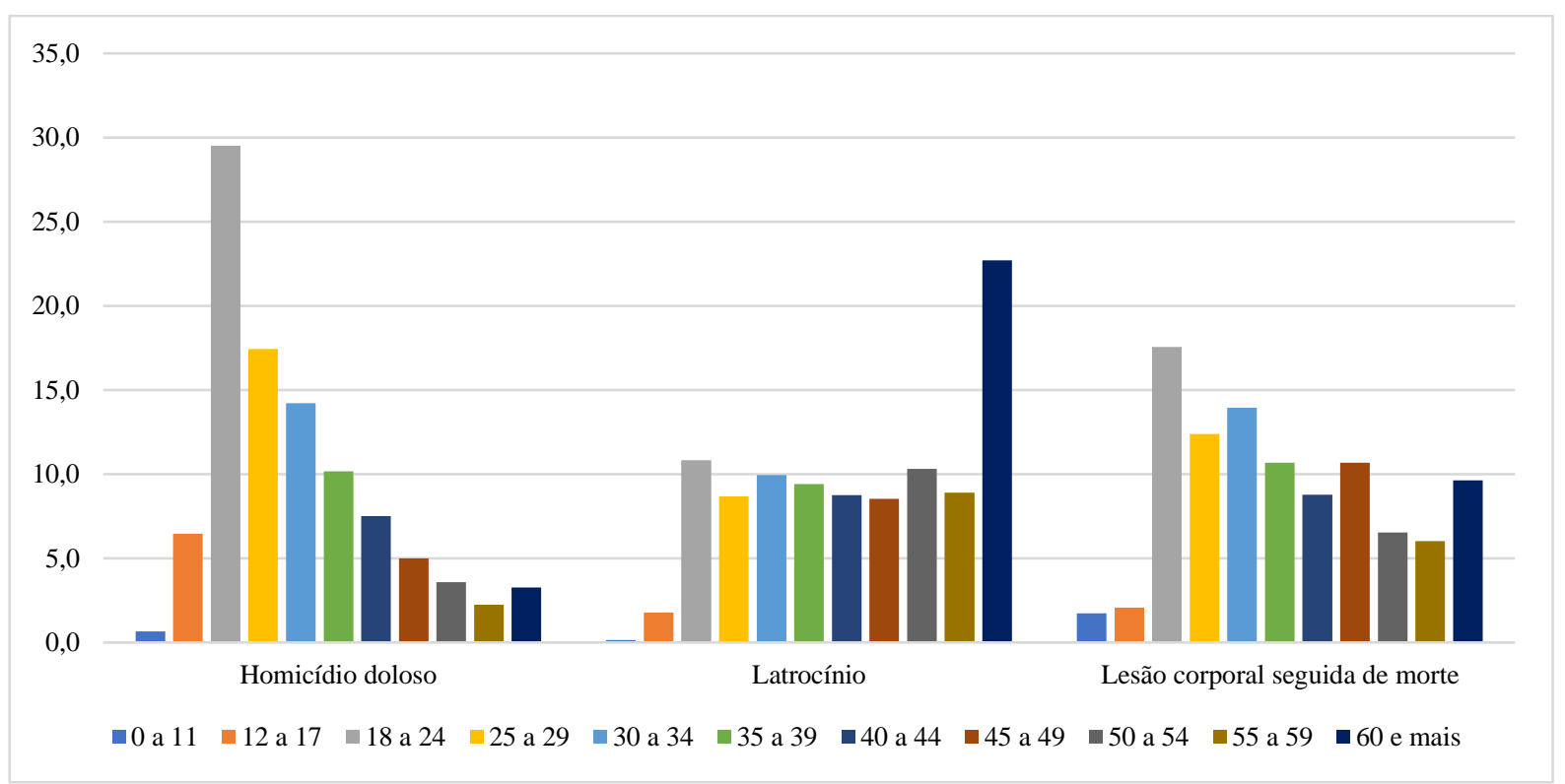

Fonte: Adaptado do $15^{\circ}$ Anuário Brasileiro de Segurança Pública (2021).

As vítimas de homicídios e lesão corporal seguida de morte estão na faixa etária de 18 a 29 anos, e os principais instrumentos empregados para o praticar esses atos violentos, com destaque para o homicídio e latrocínio, são as armas de fogo

${ }^{2}$ Taxa de mortes por grupo de 100.000 habitantes no Brasil. 
(Figura 14). Os Estados que fazem fronteira com países da América Latina são os que mais sofrem por serem rotas do narcotráfico. Isso contribui para o aumento da criminalidade violenta e circulação de armas de fogo (De Lima, Bueno \& Alcadipani, 2021).

Figura 14. Tipo de instrumento utilizado para praticar crimes violentos no Brasil em 2020.

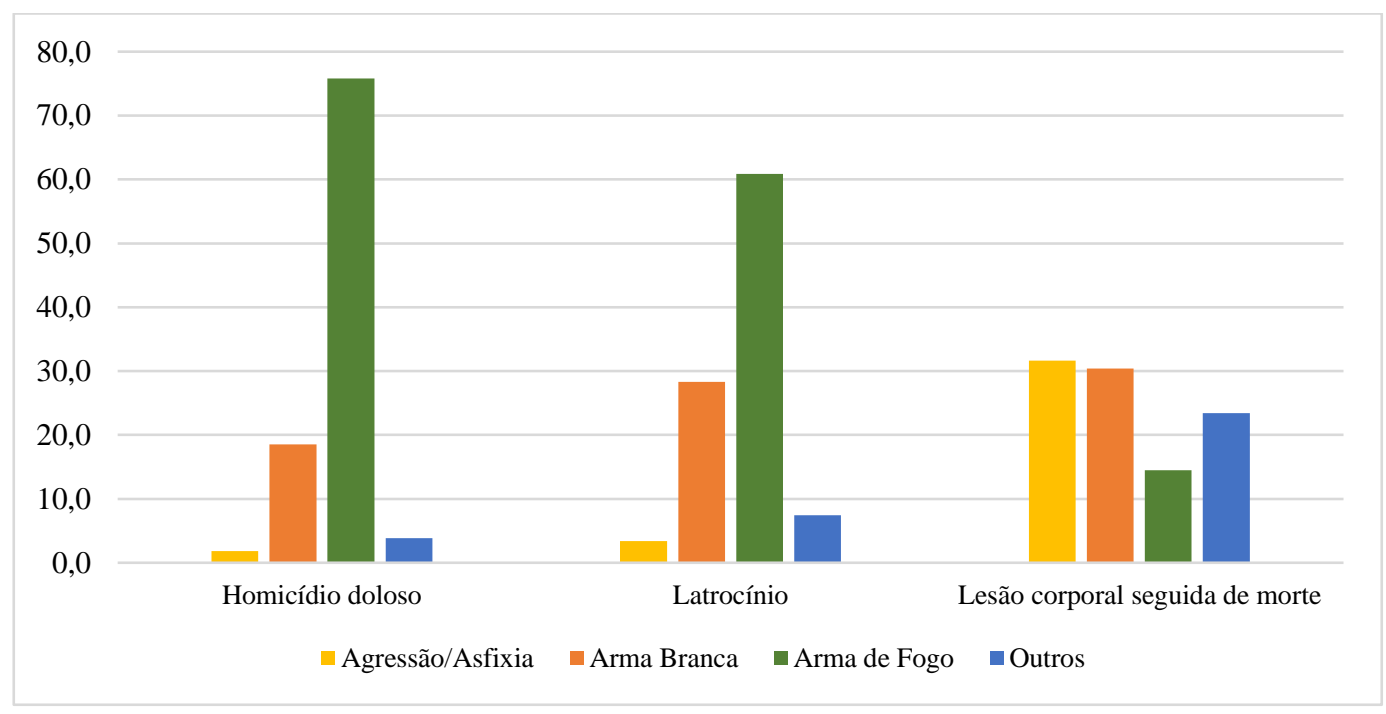

Fonte: Adaptado do $15^{\circ}$ Anuário Brasileiro de Segurança Pública (2021).

Convém observar que a taxa por grupo de 100 mil habitantes é diversificada no Brasil, e os dez estados com os quantitativos maiores de mortes, com destaque para o homicídio, concentram-se nas regiões Norte e Nordeste.

Figura 15. Taxa de homicídios por 100 mil habitantes e por estados no Brasil em 2019.

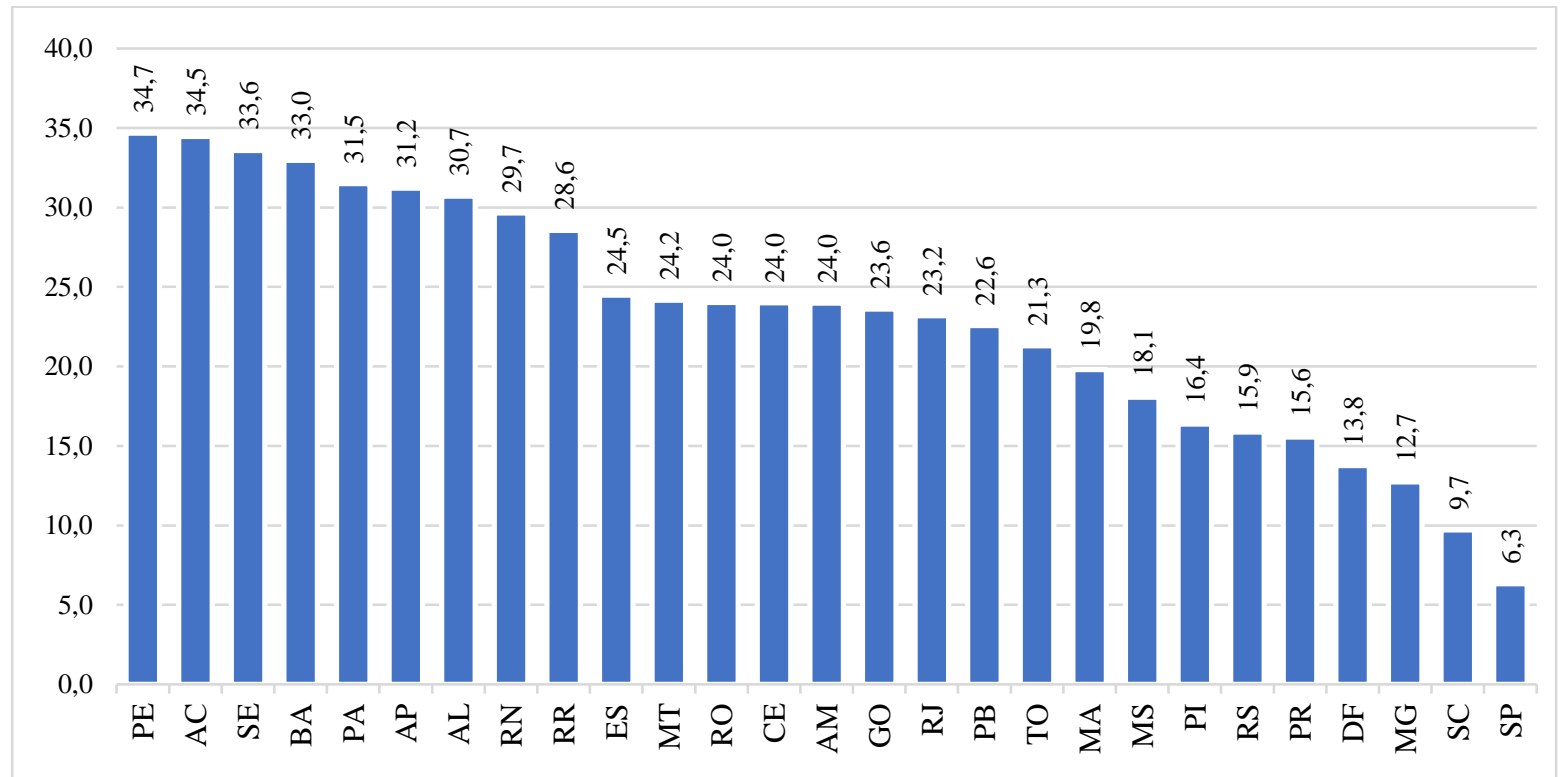

Fonte: Elaborada pelo autor com base em informações do Ipea (Adaptado do Atlas da Violência, 2021).

As regiões brasileiras possuem uma diversificação no quantitativo de MV. Quando observado o número absoluto, fica evidente que as regiões mais populosas não são necessariamente as mais violentas. A região Sudeste é um exemplo desse quadro. Diante dessas considerações, a tabela 5 apresenta os dados que mostram que as regiões Norte e Nordeste apresentam taxas por 100 mil habitantes superiores às demais. 
Tabela 5. Panorama das mortes violentas por regiões no Brasil em 2019.

\begin{tabular}{lccccccc}
\hline \multicolumn{1}{c}{ Região } & Pop.* $^{*}$ & Nr. Abs. & Freq. Rel. & Freq. Acu. & Taxa $^{3}$ & Freq. Rel. & Freq. Acu. \\
\hline Nordeste & 57.374 .243 & 18.300 & $38 \%$ & $38 \%$ & 32,1 & $26 \%$ & $26 \%$ \\
Sudeste & 89.012 .240 & 13.932 & $29 \%$ & $67 \%$ & 15,8 & $13 \%$ & $39 \%$ \\
Norte & 18.672 .591 & 6.423 & $14 \%$ & $81 \%$ & 34,8 & $28 \%$ & $67 \%$ \\
Sul & 30.192 .315 & 4.942 & $10 \%$ & $91 \%$ & 16,5 & $13 \%$ & $80 \%$ \\
Centro-oeste & 16.504 .303 & 4.179 & $9 \%$ & $100 \%$ & 25,6 & $20 \%$ & $100 \%$ \\
\hline Total & & $\mathbf{4 7 . 7 7 6}$ & $\mathbf{1 0 0 \%}$ & $\mathbf{1 0 0 \%}$ & & $\mathbf{1 0 0 \%}$ & $\mathbf{1 0 0 \%}$ \\
\hline
\end{tabular}

*População estimada para 2020 segundo o IBGE.

Fonte: Elaborada pelo autor com base em informações (Adaptado IPEA, 2021; Atlas da Violência, 2021; IBGE, 2021).

Conforme descrito anteriormente, o Amapá, Pará, Acre, Sergipe, Rio Grande do Norte e Bahia estão com índices mais altos. Em relação às capitais dos estados da região Norte do Brasil, a cidade de Rio Branco representa 42,96, Manaus, 45,13 e Macapá 56,62, contudo houve reduções significativas entre 2018 e 2019. Belém, capital do Estado do Pará, teve uma variação entre 2018 e 2019 de 45,4\% de mortes violentas intencionais, ou seja, 471 pessoas foram poupadas. A segunda capital a diminuir seus indicadores foi Boa Vista $(24,8 \%)$ seguida de Rio Branco $(24,1 \%)$.

Tabela 6. Mortes violentas intencionais nas capitais da região norte do Brasil entre 2018 e 2019.

\begin{tabular}{|c|c|c|c|c|c|c|c|c|c|}
\hline \multirow[b]{2}{*}{ Capital } & \multicolumn{4}{|c|}{2018} & \multicolumn{4}{|c|}{2019} & \multirow{2}{*}{$\begin{array}{c}2018-2019 \\
\text { Var. }(\%)\end{array}$} \\
\hline & Nr. abs. & Freq. Rel. & Taxa & Freq. Rel. & Nr. Abs. & Freq. Rel. & Taxa & Freq. Rel. & \\
\hline Belém & 1043 & $34 \%$ & 70,2 & $20 \%$ & 572 & $24 \%$ & 38,32 & $14 \%$ & $-45,4 \%$ \\
\hline Boa Vista & 175 & $6 \%$ & 46,62 & $14 \%$ & 140 & $6 \%$ & 35,07 & $13 \%$ & $-24,8$ \\
\hline Macapá & 348 & $12 \%$ & 70,5 & $20 \%$ & 285 & $12 \%$ & 56,62 & $21 \%$ & $-19,7$ \\
\hline Manaus & 1008 & $33 \%$ & 46,98 & $14 \%$ & 985 & $41 \%$ & 45,13 & $16 \%$ & $-4,0$ \\
\hline Palmas & 73 & $2 \%$ & 25,01 & $7 \%$ & 74 & $3 \%$ & 24,74 & $9 \%$ & $-1,1$ \\
\hline Porto Velho & 160 & $5 \%$ & 30,8 & $9 \%$ & 168 & $7 \%$ & 31,73 & $11 \%$ & 3,0 \\
\hline Rio Branco & 227 & $8 \%$ & 56,59 & $16 \%$ & 175 & $7 \%$ & 42,96 & $16 \%$ & $-24,1$ \\
\hline Total & 3034 & $100 \%$ & & $100 \%$ & 2399 & 100 & & $100 \%$ & $26 \%$ \\
\hline
\end{tabular}

Fonte: Elaborada pelo autor com base em informações (Adaptado do IPEA, 2021; 14º Anuário da Violência, 2021).

As capitais que menos contribuíram para a diminuição das MV foram Manaus (-4\%) e Palmas (-1,1\%). Conforme enfatizado, os jovens adultos são os que mais morrem, e esse crescimento representa um grave problema para a sociedade, pois infere-se que cada vez mais os jovens estão entrando e permanecendo no campo da criminalidade. Em relação às mortes violentas intencionais (MVI), em todas regiões do Brasil ocorreu redução dos casos, contudo as regiões Norte e Nordeste lideram o quantitativo de pessoas assassinadas no país.

Conforme pode ser observado na Figura 16, o Tocantins teve um aumento populacional em torno de $116 \%$, ou seja, a população do estado mais que dobrou. Quanto às mortes violentas no Tocantins e o aumento populacional, há de se considerar que esse ente federativo é o mais novo e poucas pesquisas relacionadas à criminalidade foram realizadas. Partindo desse princípio, e diante da necessidade de pesquisar esse fenômeno nessa unidade federativa, evidenciamos o crescimento populacional e o aumento das MV. 
Figura 16. Crescimento populacional do Estado do Tocantins entre 1980 e 2020.

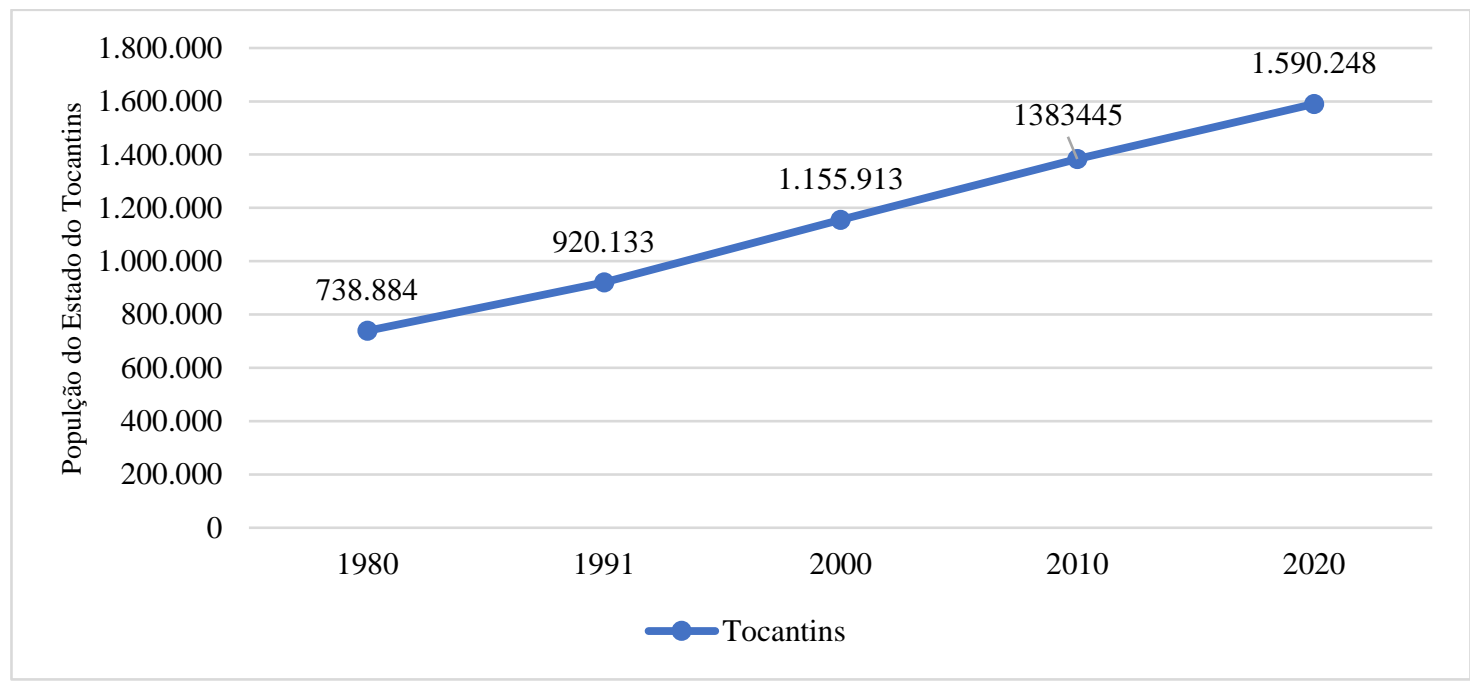

Fonte: Elaborada pelo autor com base em informações do Censo de 2010 do IBGE (IBGE, 2020).

Em relação aos crimes de homicídio doloso, latrocínio e lesão corporal seguida de morte, o estado do Tocantins teve uma variação de $21 \%$ entre 2011 a 2019. Quando se refere somente aos casos de homicídio, o aumento é de $623 \%$ entre 1989 e 2019 (Figura 17). Dessa maneira, o Estado do Tocantins repete o cenário da região norte do Brasil onde mais pessoas estão se envolvendo com a criminalidade e principalmente com tráfico de drogas e organizações criminosas. Presume-se que o espaço social da criminalidade, aqui apresentado como um local de disputas, onde os mais fortes se sobressaem, é característica das principais cidades do Brasil. Nessa perspectiva, esse trabalho procurou apresentar características e semelhanças entre as vítimas de MVI e APL, com informações e dados de diversas fontes, objetivando contribuir com estudos e ações para reduzir a criminalidade violenta.

Figura 17. Série histórica de mortes violentas no Estado do Tocantins de 1989 a 2019 em números absolutos.

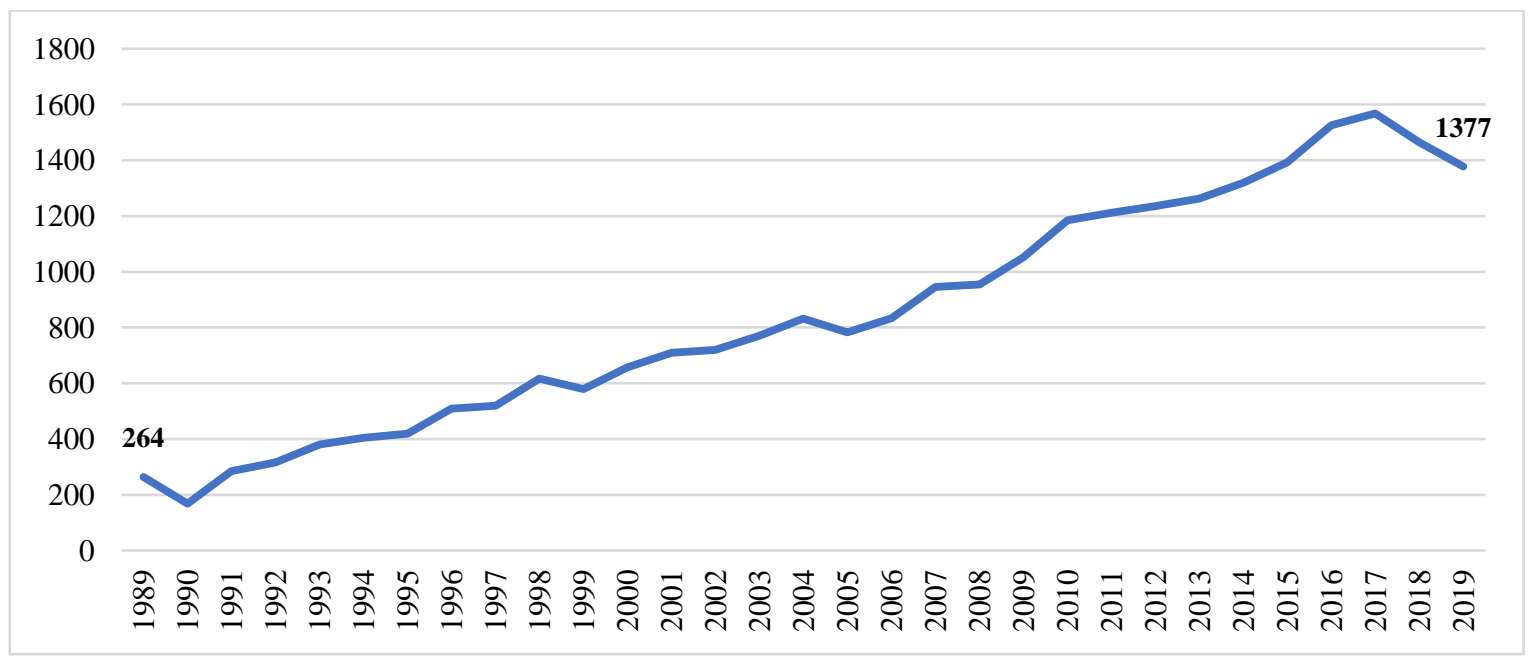

Fonte: Elaborada pelo autor com base em informações do Ipea (Adaptado, IPEA, 2020).

Conforme exposto, os crimes violentos aqui identificado como homicídio doloso, latrocínio e lesão corporal seguida de morte são um problema em todas as regiões do Brasil. Face aos dados e informações aqui destacadas, presume-se que a criminalidade violenta no Brasil danifica e consome as estruturas sociais, pois a maior parte das pessoas que cometem crimes e que mais morrem em decorrência dessa causa são indivíduos entre 18 a 29 anos. 


\section{Considerações Finais}

Fundamentado nos dados e informações descritos ao longo deste texto, pode-se afirmar que os criminosos no Brasil possuem características e perfis semelhantes ou quase congêneres em todo o território nacional, ou seja, os criminosos são agentes com idade entre 18 a 45, são solteiros, com baixa escolaridade, sua carreira criminal se inicia com o tráfico de drogas, pois se trata do crime mais praticado no Brasil, seguido dos crimes contra a propriedade (furto, roubo, estelionato), chegando ao ápice da criminalidade violenta, com as mortes violentas ou crimes letais intencionais (homicídio doloso, latrocínio e lesão corporal seguida de morte).

Enquanto isso, as vítimas de mortes violentas são jovens entre 18 a 29 quando se referem a homicídios, ao passo que quanto aos crimes de latrocínio (roubo seguido de morte), as vítimas são as pessoas idosas acima de 60 anos. Em relação à lesão corporal seguida de morte, os que são mais vitimados são as pessoas entre 18 a 34 anos. Cabe frisar que as pessoas autodeclaradas pardas/negras são mais vitimadas.

Os resultados sugerem que a criminalidade violenta no Brasil possui características e circunstâncias que afetam todas as cidades e vitima diversas pessoas, de crianças a idosos (Figura 13), através de homicídio, latrocínio ou lesão corporal seguida de morte, com o uso de arma de fogo, arma branca ou agressão. Os agentes que cometem os crimes e estão presos são adultos com idade entre 18 a 34 anos, são solteiros, autodeclarados pardos, com baixa escolaridade e as maiores incidências criminais são o tráfico de drogas.

\section{Referências}

Asmann, P., \& O'Reilly, E. (2020). Insight Crime Balance of Homicides in 2019. InSight Crime, 8. https://insightcrime.org/news/analysis/insight-crime-2019homicide-round-up/.

Campos, L. M., \& Santos, N. D. (2004). O Crime Organizado e as prisões no Brasil.Artigo Científico, CONPEDI, ciências penais UFG. https://www2.mp.pa.gov.br/sistemas/gcsubsites/upload/60/O\%20Crime\%20Organizado\%20e\%20as\%20pris\%C3\%83\%C2\%B5es\%20no\%20Brasil.pdf.

Carneiro, L. de A., \& Silva, M. A. da R. (2020). Desafios e perspectivas de políticas públicas na redução de crimes violentos letais intencionais no Norte do Brasil. Research, Society and Development, 9(11), e61791110178. https://doi.org/10.33448/rsd-v9i11.10178.

Carneiro, L. de A., \& Oliveira, N. M. de. (2020). Crimes violentos e suas implicações no desenvolvimento regional: uma revisão da literatura. Research, Society and Development, 9(6), e199963626. https://doi.org/10.33448/rsd-v9i6.3626

Costa, A. T. M., \& Lima, R. S. (2018). Estatísticas oficiais, violência e crime no Brasil. BIB, 84, 81-106. https://anpocs.com/index.php/bib-pt/bib-84/11101estatisticas-oficiais-violencia-e-crime-no-brasil/file.

De Lima, R. S., Bueno, S., \& Alcadipani, R. (2021). Evolução das mortes violentas intencionais no Brasil. In. de Segurança Pública, A. B. (2021). Fórum Brasileiro de Segurança Pública (p. 21-35). https://forumseguranca.org.br/wp-content/uploads/2021/10/anuario-15-completo-v7-251021.pdf.

Edelstein, A. (2016). Repensando as definições conceituais da carreira do criminoso e da criminalidade serial. Trauma, Violence, \& Abuse, 17 (1), 62-71. DOI. https://doi.org/10.1177\%2F1524838014566694.

Fórum Brasileiro de Segurança Pública (2021). Anuário Brasileiro de Segurança Pública. https://forumseguranca.org.br/anuario-brasileiro-seguranca-publica/.

Gerhardt, T. E., \& Silveira, D. T. (2009). Métodos de pesquisa. Plageder. E-books.google.com.

IPEA - Instituto de Pesquisa Econômica Aplicada. Atlas da violência (2021). https://www.ipea.gov.br/atlasviolencia/.

Misse, M. (2006). Crime e violência no Brasil contemporâneo. Estudos de sociologia do crime e da violência urbana, Editora Lúmen Juris.

Monitor da Violência. (NEV-USP). Mortes violentas mês a mês no país. http://especiais.g1.globo.com/monitor-da-violencia/2018/mortes-violentas-no-brasil/.

Nóbrega Júnior, J. M. P. D., Zaverucha, J., \& Rocha, E. C. D. (2009). Homicídios no Brasil: revisando a bibliografia nacional e seus resultados empíricos. Revista Brasileira de Informação Bibliográfica em Ciências Sociais, 75-94.

Núcleo de Estudos da Violência da USP (NEV-USP). https://nev.prp.usp.br/sobre/institucional/.

Ribeiro, L., Martino, N., \& Duarte, T. L. (2021). Antes das grades: perfis e dinâmicas criminais de mulheres presas em Minas Gerais. Sociedade e Estado, 36, 639-665. DOI. https://doi.org/10.1590/s0102-6992-202136020012.

Sapori, L. F. (2019). Crônicas de uma falácia auto cumprida. In. de Segurança Pública, A. B. (2019). Fórum Brasileiro de Segurança Pública (p. 200-202). 
Research, Society and Development, v. 11, n. 2, e23711225704, 2022

(CC BY 4.0) | ISSN 2525-3409 | DOI: http://dx.doi.org/10.33448/rsd-v11i2.25704

Soares Filho, A. M., Merchan-Hamann, E., \& Vasconcelos, C. H. (2020). Expansão, deslocamento e interiorização do homicídio no Brasil, entre 2000 e 2015: uma análise espacial. Ciência \& Saúde Coletiva, 25, 3097-3105. https://doi.org/10.1590/1413-81232020258.32612018.

Tavares, R., Catalan, V. D. B., Romano, P. M. D. M., \& Melo, E. M. (2016). Homicídios e vulnerabilidade social. Ciência \& Saúde Coletiva, $21,923-934$. Disponível em: https://doi.org/10.1590/1413-81232015213.12362015.

Tocantins, (2020) Secretaria de Cidadania e Justiça do Estado do Estado do Tocantins. https://www.to.gov.br/cidadaniaejustica. 